\title{
Sustainable digital technologies in the management of infrastructure property complexes
}

\author{
Petr Kozin ${ }^{1}$, Natalia Alekseeva ${ }^{2, *}$, and Svetlana Krechko ${ }^{3}$ \\ ${ }^{1}$ Emperor Alexander I St. Petersburg State Transport University, 9 Moskovsky pr., 190031, \\ St.Petersburg, Russia \\ ${ }^{2}$ Peter the Great St.Petersburg Polytechnic University (SPbPU), Polytechnicheskaya, 29, 195251, \\ St.Petersburg, Russia \\ ${ }^{3}$ Yanka Kupala State University of Grodno, 22 Ozheshko str., 230023, Grodno, Belarus
}

\begin{abstract}
The existing procedure for regulating property relations, built on the basis of the concept of market equilibrium, requires updating on the basis of a mechanism for preparing and making fair decisions, taking into account the wide opportunities for analysis through the use of artificial intelligence. We continue and develop the presented research by describing the implementation of the decision-making preparation mechanism based on the creation of a financial digital twin of the marine infrastructure property complex. The purpose of this study is to consider options and digital mechanisms for making management decisions on the development of infrastructure property complexes that are justified from an economic point of view, as well as from the point of view of public efficiency. The following tasks are solved: define a regional marine property complex as a type of infrastructure property complex; create criteria for evaluating the effectiveness of the regional marine infrastructure property complex; describe the implementation of the mechanism for preparing for decisionmaking based on the creation of a financial digital double of the research object. Mechanisms of support for managerial decision-making using artificial intelligence based on neural network construction are considered. The scientific novelty lies in the fact that the study offers an effective mechanism for preparing and making decisions, implemented on the basis of creating a financial digital double of the marine infrastructure property complex.
\end{abstract}

\section{Introduction}

In the works of scholars on issues related to professional property management and property complexes in the Russian Federation, in early 2000, it was noted that the problems of property management of the Russian Federation, typical of St. Petersburg are [1]:

- $\quad$ accelerated aging improvements due to poor quality of operation;

- $\quad$ lack of a system for restoring the worn-out part of buildings and communications;

\footnotetext{
${ }^{*}$ Corresponding author: natasha-alexeeva@yandex.ru
} 
- prevalence of a limited set of management decisions that are not provided with reliable criteria for applicability and performance evaluation;

- $\quad$ low environmental operating standards [2].

At the same time, it is noted that these and other shortcomings in the management system of infrastructure marine facilities lead not only to budget losses [3], but also to an increase in social tension among stevedores around making decisions about these objects.

Moreover, in the same place [1] it is stated that the choice of use cases, including commercial objects, should be based on the cumulative effect (financial effect and social utility). Public utility in this case is associated with positive "external effects" for the region: creating new or improving the efficiency of existing business conditions, economic development of the territory or improving the environmental situation.

Unfortunately, it should be noted that these issues have not been resolved to date. The fact is that the mechanisms of market self-regulation and search for balance in this case are ineffective. Private owners are guided by commercial interests when disposing of real estate and do not assess the social and social impact. Similarly, existing legislation does not oblige government agencies to analyze possible consequences for related industries or calculate the economic and social impact when making certain decisions.

Poor quality of decisions made in relation to marine infrastructure property complexes leads to the following negative consequences:

- deterioration of the environmental situation in the subject of the Russian Federation: an increase in hazardous emissions into the air and water environment (when making management decisions, the impact on the environment is not taken into account);

- deterioration of accessibility of transport infrastructure in adjacent territories: traffic jams (when making management decisions, infrastructure criteria are not used);

- deterioration of the quality of port infrastructure: increased depreciation of fixed assets, including utility networks and wave protection infrastructure (when making management decisions, criteria that take into account the life cycle of objects are not used);

- refusal to bear business risks by transferring them to the investor: increase in budget expenditures (when making management decisions, the criteria for assessing the risks of project implementation are not used, which are compensated in the future by the growth of budget investments).

Digital technologies offer great opportunities for improving management mechanisms and processes. Seaports as large property complexes that provide foreign economic activity are the subject of wide study as a fundamental [4-6], and practical points of view in order to introduce advanced technologies in their activities. In [7] an assessment of the implementation of blockchain technology as a tool for accelerating capabilities within the smart port network is presented. In [8] discusses the use of IoT solutions in intelligent transport systems to automate data processing. In [9] discusses the processes of supply management in multimodal logistics complexes. The presented works are aimed at increasing the efficiency of processes and operations, environmental friendliness and social aspects.

We continue and develop the presented research by describing the implementation of the decision-making preparation mechanism based on the creation of a financial digital twin of the marine infrastructure property complex.

Thus, the purpose of this study is to consider options and digital mechanisms for making managerial decisions in the management of infrastructure property complexes that are justified from an economic point of view, as well as from the point of view of public efficiency. At the same time, it seems that in modern conditions, the object of research cannot be a single real estate object, several or many objects. It is necessary to proceed to the analysis of separate economic entities - infrastructure property complexes (one of the types of which is regional marine property complexes). Such a representation will allow us to properly take into account the social effects of the implementation of certain projects, which in the current 
situation may acquire socio-economic significance, which exceeds the significance of the calculated indicators of economic efficiency currently used when choosing the best project [10].

Thus, to achieve this goal, the following tasks are solved:

1. Define a regional marine property complex as a type of infrastructure property complex.

2. Create criteria for evaluating the effectiveness of the regional marine infrastructure property complex.

3. Describe the implementation of the mechanism for preparing for decision-making based on the creation of a financial digital double of the research object.

\section{Materials and Methods}

The paper uses basic methods of General scientific and natural science cognition. The main methods in the work are the observation method, the abstraction method, and the logical method.

In this paper we analyzed a significant number of sources, including regulatory ones, which provide ways to assess the effectiveness of the property complex and its components:

- $\quad$ strategic planning documents [11];

- $\quad$ documents the administrative regulation [12];

- national and international rating systems (national investment rating from the Agency for strategic initiatives for the promotion of new projects [13], as well as a similar "Doing Business" rating by the World Bank [14]).

At the same time, these assessments and ratings are politicized, do not contain a calculated economic model for the implementation of positive proposals, and failures in certain areas are subsequently explained by unpredictable external factors. Thus, according to expert estimates of the authors of the relevant strategies, the average level of implementation of measures included in the Strategy-2010 was 36\%, in the Strategy-2020-29.5\%, and the share of fully implemented measures in the Strategy-2020 was $6.8 \%$ [15].

The following open data sources are currently available (Table 1).

Table 1. Sources of open data for assessing the effectiveness of the use of the marine property complex.

\begin{tabular}{|c|c|}
\hline Data sourse & Web-site \\
\hline $\begin{array}{c}\text { Unified state system of information on the } \\
\text { situation in the world ocean }\end{array}$ & $\mathrm{http}: / /$ esimo.ru/portal/ \\
\hline Russian Maritime register of shipping & $\mathrm{https}: / /$ rs-class.org/ \\
\hline Russian river register & $\mathrm{https:/www.rivreg.ru/}$ \\
\hline Federal state statistics service & $\begin{array}{c}\mathrm{http} / / \text { www.gks.ru/ } \\
\mathrm{http}: / / \text { fedstat.ru }\end{array}$ \\
\hline Open data Portal of the Russian Federation & $\mathrm{https} / /$ data.gov.ru/ \\
\hline Open data Portal of Saint Petersburg & www.data.gov.spb.ru \\
\hline
\end{tabular}

\section{Results}

\subsection{The concept of regional marine property complex}

In order to implement a systematic approach to the study of these phenomena, we will determine at which level of development or scale of real estate objects such issues can be 
resolved. Under development in this case, we will understand the process of qualitative transformation of any matter, environment, or other formation aimed at improving and complicating their characteristics or at converting from quantity to a new, qualitatively better state [16].

Level I: berth (as part of the mooring front) - the minimum real estate object that is subject to civil turnover.

Level II: capital construction object - a set of mooring lines, the quantitative characteristics of which are transferred to a new quality. The object can be reconstructed, repurposed, or otherwise improved.

Level III: stevedoring zone - a set of objects that allows combining objects of various functional purposes to compensate for short-term fluctuations in market conditions for certain types of objects.

Level IV: regional property complex or infrastructure property complex (Corporation) a set of portfolios of objects that have the properties of self-organization, extended reproduction, and separate management. A regional property complex is an analog of an enterprise in [17], which includes all types of property and property rights, including land, buildings, structures, equipment, raw materials, products, claims, debts, rights to work and services. The regional Maritime property complex covers all areas of activity of the port complex, so it is at this stage of development that social obligations and the need to comply with public interests arise. When we talk about the regional Maritime property complex, it is also necessary to take into account all financial resources related to port activities in the region, including budget funds. Unlike an enterprise, a regional marine property complex is not subject to registration, but acts as an economic entity through the relevant authorities and organizations. In turn, a regional marine property complex may include marine property complexes of various scales.

Level V: state property complex (transnational corporations) - a set of regions that perform the function of strategic self-determination, as well as determine their role in interaction with other States. To do this, they need to set performance criteria for themselves and for contractors. In relation to infrastructure and marine property complexes, this level represents the entire marine industry of a state or a set of States in a region or water basin.

\subsection{Evaluation criteria efficiency}

It should be noted that the need to take into account social factors when making economic decisions is confirmed by the transition to behavioral Economics, described in the works of modern economists - Nobel prize winners in Economics Akerlof [18] and Taler [19].

What should be the criteria for evaluating the effectiveness of the use of the marine infrastructure property complex, taking into account the described features?

The data sets presented in sources from Table №1 do not contain unambiguous criteria for evaluating the effectiveness of the use of the marine property complex, since there are no estimates of the social effect and the degree of satisfaction of social needs. At the same time, the required criteria can be established on the basis of statistical processing of big data on financial transactions of economic entities and identification of social and social trends in the port community and the region. Forecasts of the use of big data in the Russian Federation have great potential and can be used for making management decisions related to performance assessment [20]. Arrays of information for such processing can be obtained from two sources:

1. Data on tax reporting and financial transactions of economic entities of the port zone. The information contained in them can provide significant support in modeling financial and economic processes. 
2. Information about the state of physical objects of the port infrastructure obtained through the operation of RFID sensors. The information contained in them can provide significant support in modeling economic processes. The sensors themselves can later become the basis for creating an Internet of things network for the marine infrastructure property complex.

The issue of reproduction of state-owned port property can be resolved by forming and including infrastructure facilities in stevedoring zones along with" profitable " facilities with stable rent receipts, as well as objects in unsatisfactory condition that require repair.

After defining a clear list of criteria for evaluating decision options, the task of building a mechanism for preparing for decision-making can be formulated as a multi-criteria one, taking into account: terms, costs, budget effect, public effect, commercial effect, efficiency of control within the life cycle, and other certain factors.it is solved on the basis of processing large amounts of data using artificial intelligence in the framework of building an artificial neural network. It should be noted that the implementation of such a mechanism for preparing for decision-making has become possible only recently due to the breakthrough development of digital technologies that have provided the availability of digital data for analysis and the ability to implement their processing in a volume previously inaccessible to the human brain. We describe the first steps of building a financial digital double of the research object implemented by a neural network.

\subsection{Mechanism for preparing for decision making based on the creation of a financial digital double of the research object}

Let's consider the following example of using a single-level artificial neural network as a mechanism for preparing for making a decision on the disposal of a level II marine property complex-the mooring front (see Fig. 1).

\section{Example of using a single-level neural network}

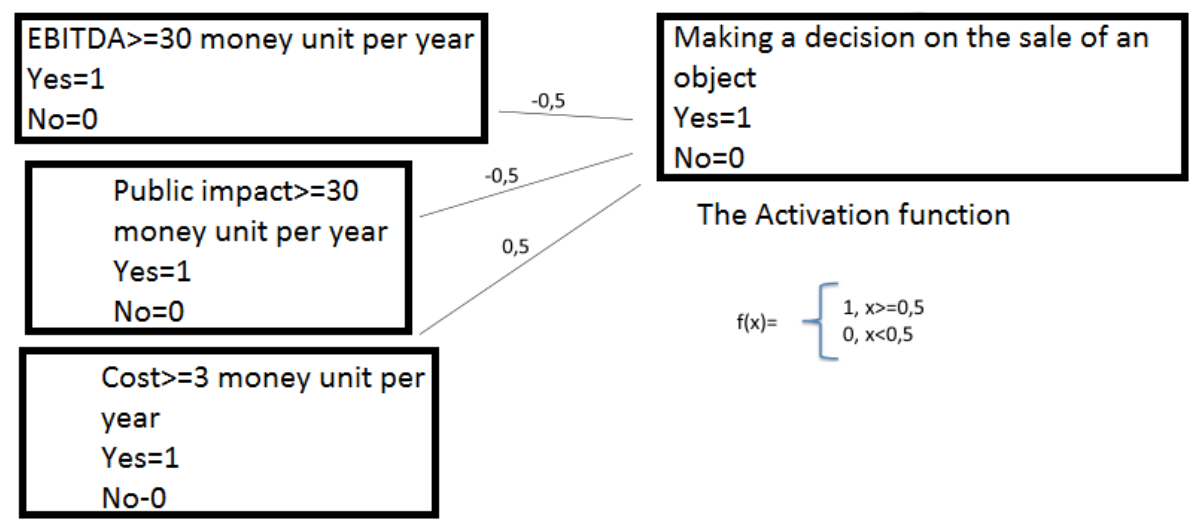

Fig. 1. Example of using a single-level neural network to prepare for making a decision on the disposal of the mooring front (compiled by the authors).

For Fig. 1 a single-level artificial neural network is presented that reflects the mechanism of preparation for making a simple decision: to sell a hydraulic structure or not to sell it, depending on the following conditions:

- $\quad$ EBITDA in case of commercial use, monetary units/year; 
- the ability to adapt the object for a social function or for state needs, which will save budget funds in the specified amount of monetary units / year;

- the amount of expenses for the maintenance of the object, monetary units / year;

The weight coefficients and activation function for all neurons are selected in such a way that:

- $\quad$ expensive objects that have prospects for commercial or related infrastructure usewere sold;

- $\quad$ objects that have prospects for state or related infrastructure use, regardless of the amount of costs - were not sold.

However, in reality, there may be various combinations of situations, in each of which it is necessary to establish a rule for choosing the preferred solution in order to exclude the determining influence of the subjective factor of decision-making and to ensure uniformity and fairness. This model allows you to do this by adding a second layer of "generalizations" - pairwise comparisons for every 2 factors (see Fig. 2). With the growing number of factors and variants of generalizations, such a problem cannot be solved by a person without the involvement of modern digital technologies. This model also allows you to introduce any type of exceptions when making decisions, including them in the neural network as an additional layer, which will also ensure transparency and verifiability of their application. Thus, we can talk about creating a digital financial double of the analyzed mooring front.

\section{Example of using a two-level neural network}

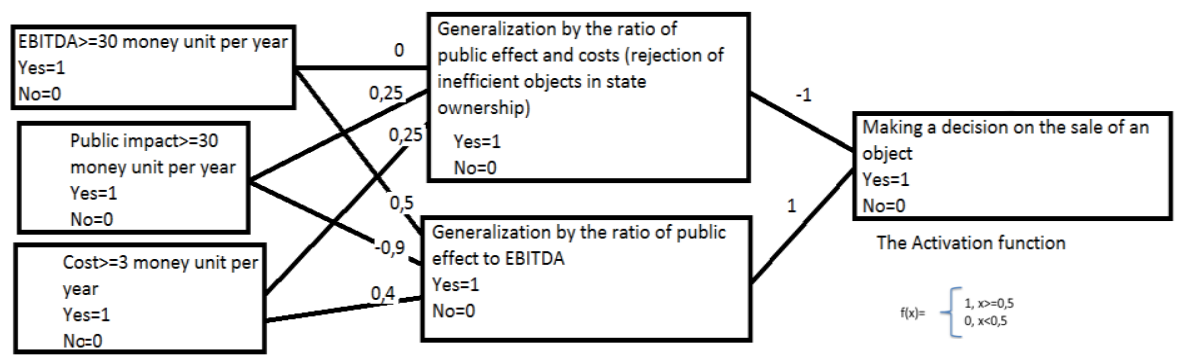

Fig. 2. Consideration of preferences in a two-level neural network when preparing and making decisions (compiled by the authors).

As you can see from this example, when preparing and making a decision, you can set:

- criterion for the ratio of social effect and costs (refusal of inefficient objects in the Treasury);

- $\quad$ criteria for the ratio of social effect and profit after tax (you can set a priority: what is more important for the budget - to get income or meet a public need).

Building such an artificial neural network taking into account all possible criteria for evaluating efficiency (public, budget, commercial), followed by the introduction of a layer of neurons to set priorities in each of the pairs of criteria - is the desired mechanism for an objective and transparent procedure for determining the effectiveness of the use of the property complex.

The issue of setting priorities-weight coefficients can be solved independently in the following ways:

- $\quad$ appointment of experts (in fact, at present the Legislative Assembly of St. Petersburg determines the priorities of budget policy in an expert manner: which industries require additional funding);

- the training of the neural network as shown in Fig. 3 in this case, it is necessary to set the maximum permissible deviation and set weight coefficients to ensure the specified 
level according to the criterion described above (the maximum share of fair decisions made in accordance with the established mechanism).

\section{Neural network training scheme (getting weights)}

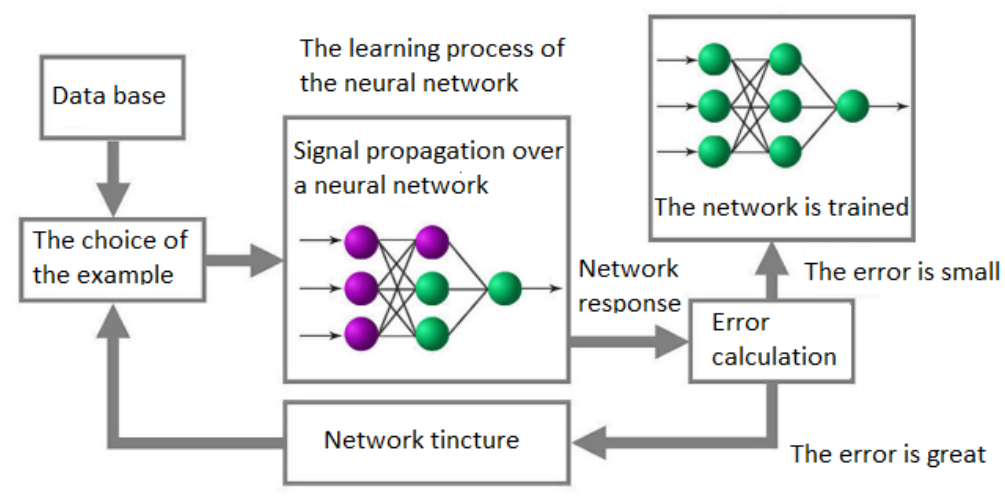

Fig. 3. Training scheme of the neural network (compiled by the authors).

\section{Discussion}

The scientific novelty lies in the fact that the study offers an effective mech-anism for preparing and making decisions, implemented on the basis of creat-ing a financial digital double of the marine infrastructure property complex.

The search for a mechanism for harmonizing state, commercial and public interests is particularly relevant in times of crisis, which we are seeing now. Such a mechanism developed in the article will be in demand in various areas of the economy, and may have an impact on the further development of research in the field of efficiency of investment projects.

In world practice, there are examples of developed systems for evaluating public performance (Germany) or commercial performance (USA), but the mechanism for balancing the interests of the entire society is poorly developed, and therefore the result of this study is scientifically significant and all new.

\section{Conclusions}

As a result of the study, we will outline the following main conclusions:

The existing procedure for regulating property relations, built on the basis of the concept of market equilibrium, requires updating on the basis of a mechanism for preparing and making fair decisions, taking into account the wide opportunities for analysis through the use of artificial intelligence.

The object of property regulation is an infrastructure property complex that includes all types of property and property rights, including land plots, buildings, structures, equipment, raw materials, products, claims, debts, rights to works and services, the management mechanism of which can be implemented by creating a financial digital double.

Building a mechanism for preparing and making decisions on the distribution of property resources is a multi-criteria task that is solved on the basis of processing large amounts of data using artificial intelligence in the framework of creating an artificial neural network. Thus, the specific result of the research is the development of an effective mechanism for 
preparing and making decisions, implemented on the basis of creating a financial digital double of the marine infrastructure property complex.

\section{References}

1. E.S. Ozerov, Economics and real estate management (St. Petersburg, MKS, 2003)

2. V. Orlova, I. Ilin, S. Shirokova, MATEC Web of Conferences 193, 05055 (2018) https://doi.org/10.1051/matecconf/201819305055

3. S.V. Pupentsova, N.S. Alekseeva, O.A. Stroganova, IOP Conference Series: Materials Science and Engineering 753, 032026 (2020) DOI: 10.1088/1757-899X/753/3/032026

4. D. Skripnuk, International Journal of System Assurance Engineering and Management 11, 100-110 (2020) https://doi.org/10.1007/s13198-019-00895-6

5. A.I. Rudskoy, A.I. Borovkov, P.I. Romanov, O.V. Kolosova, Higher Education in Russia 28, 9-22 (2019) https://doi.org/10.31992/0869-3617-2019-28-2-9-22

6. S.A. Dyatlov, N.I. Didenko, O.S. Lobanov, S.V.Kulik, IOP Conference Series: Earth and Environmental Science 302, 012102 (2019) https://doi.org/10.1088/1755$1315 / 302 / 1 / 012102$

7. S. Maydanova, I. Ilin, A. Lepekhin, Proceedings of the 33rd International Business Information Management Association Conference, IBIMA 2019: Education Excellence and Innovation Management through Vision 2020, 5103-5111 (2019)

8. A.I. Levina, A.S. Dubgorn, O.Y. Iliashenko, European Conference on Electrical Engineering and Computer Science (EECS), 351-355 (2017)

9. S. Krasnov, E. Zotova, S. Sergeev, A. Krasnov, M. Draganov, IOP Conference Series: Materials Science and Engineering 618, 012069 (2019) https://doi.org/10.1088/1757899X/618/1/012069

10. P.P. Kozin, Innovations and investments 9, 198-206 (2019)

11. On the strategy of socio-economic development of Saint Petersburg for the period up to 2035 (Russian Federation)

12. About the estimation of efficiency of activity of the higher officials (heads of higher Executive bodies of state power) of subjects of the Russian Federation and enforcement authorities of subjects of the Russian Federation (Russian Federation)

13. National investment rating, https://asi.ru/investclimate/rating.

14. Doing Business, https://russian.doingbusiness.org/ru/doingbusiness.

15. National investment rating, http://2035.media/2017/09/27/strategy2020-part1.

16. I.M. Anisimov, Management of territory development (Ultra Print, Saint Petersburg, 2011)

17. Civil code (Russian Federation)

18. G.A. Akerlof, R.J. Shiller, Animal Spirits: How Human Psychology Drives the Economy, and Why It Matters for Global Capitalism (Princeton University Press, 2010)

19. R.H. Thaler, Misbehaving: The Making of Behavioral Economics (W.W. Norton \& Company, 2016)

20. A.I. Klimin, N.V, Pavlov, A.M., Efimov, Z.L. Simakova, Proceedings of the 31 st International Business Information Management Association Conference (2018) 